\title{
LITERATURA E PRÁTICA PEDAGÓGICA REFLEXIVA NO ENSINO FUNDAMENTAL: A HORA DO CONTO NO CEPAE
}

\author{
Simei Araujo Silva ${ }^{1}$ \\ Sílvia Rosa Silva Zanolla ${ }^{2}$
}

Resumo: O presente trabalho objetivou investigar a identificação dos alunos do $1 .^{\circ}$ e do $3 .^{\circ}$ ano da I Fase do Ensino Fundamental do CEPAE/UFG (Centro de Ensino e Pesquisa Aplicada à Educaçáo) com personagens e conteúdos de histórias narradas na atividade "Hora do Conto" na biblioteca (e de outras histórias conhecidas por eles em seu contexto familiar). De um total de sessenta e um alunos, dos dois terceiros anos, foram realizadas vinte e uma entrevistas, correspondendo a $34,43 \%$. Foram também entrevistados dois profissionais, dessa mesma fase da área de Ciências Humanas. Fizemos a observação da "Hora do Conto" na biblioteca no período de três meses. Na escola pesquisada, presenciou-se um ambiente literário propício para formar os contadores de histórias e leitores críticos. Partimos do pressuposto de que a literatura infantil é um recurso fundamental para a formação de valores na criança, especialmente quando se considerou seu aspecto ambivalente: a tensão entre indivíduo e sociedade. Assim, o critério de escolha do livro literário pelo professor e contador de histórias é essencialmente político, pois o conteúdo do texto literário tanto pode reafirmar a ideologia do sistema dominante, adaptando-se a ele, quanto possibilitar ao leitor infantil constituir um pensamento crítico. Recorremos aos teóricos da Teoria Crítica da Sociedade, como Adorno, Horkheimer e Benjamin, para fundamentar essa discussão. Os conceitos de sociedade, educação, ideologia e experiência constituem suportes teóricos norteadores para a análise dos dados empíricos deste trabalho, como também para a reflexão da prática pedagógica do professor. A experiência demonstra que, para as crianças, a literatura, de um lado, revela aspectos utilitários, como seu auxílio para o desenvolvimento da leitura e escrita, e, de outro, contribui para instigar a fantasia e a imaginação, o que lhes possibilitou o exercício do pensamento crítico. Pressupóe-se que a literatura, concebida como arte, possibilita à criança criar novas experiências, isto é, construir reflexóes e pensamentos críticos sobre valores da cultura dominante, valores estes que pairam em seu contexto social, sobretudo escolar e familiar.

Palavras-chave: Teoria Crítica. Literatura infantil. Prática pedagógica.

1 Graduada em Pedagogia/FE/UFG, Mestrado e Doutorado em Educação/FE/UFG. Professora efetiva na Universidade Federal de Goiás/Faculdade de Educação. Integrante do Núcleo de Estudos e Pesquisas sobre Violência, Infâncias, Diversidade e Arte/NEVIDA/FE/UFG.

2 Psicologia Social e educação. Psicologia social e escolar. 


\title{
LITERATURE AND REFLEXIVE PEDAGOGIC PRACTICE ON THE ELEMENTARY SCHOOL: STORYTELLING TIME AT CEPAE
}

\begin{abstract}
This article researched the identification of students on the first and third years of Elementary school phases 1 at CEPAE/UFG (Centro de Ensino de Pesquisa Aplicada à Educação) with characters and subjects narrated during the "Storytelling Time" activity at CEPAE's library. It also observed how students identified themselves with stories they brought from their own family context. Of 61 students from the third year, 21 were interviewed. They correspond to $34,43 \%$ of the group. Two professionals from the Humanities area were also interviewed. The observation of the "Storytelling Time" lasted three months. At CEPAE, it was possible to notice a literary environment that propitiated the formation of storytellers and critical readers. This work bases itself on the fact that children's literature is an important resource for the creation of values on children. It focuses on the ambivalent aspect of this kind of literature, which is shown when it portrays tensions between an individual and the society he lives in. Therefore, the choosing of a literary book by the teacher or by the storyteller is a political act that might reaffirm the ideology of the dominating system, adapting itself to this very system, or it might allow its reader, the child, to develop critical thinking. The article uses conceptions from Adorno, Horkheimer and Benjamin to justify this discussion. The concepts of society, education, ideology and experience guide the data analysis as well as the teacher's pedagogic practice. Experience shows that, for children, literature has useful aspects such as the development of reading and writing as well as it helps them to build up their imagination and fantasy skills, which allows critical thinking. So, literature is seen as an art which allows children to live new experiences by generating reflections and critical thinking about the dominant culture that surrounds their social, familiar and school contexts.
\end{abstract}

Keywords: Critical Theory. Children's literature. Pedagogic practice.

\section{Introduçáo}

Este texto integra parte de estudo, pesquisa e reflexões realizadas na tese de doutorado defendida no ano de 2012 no Programa de Pós-Graduação Stricto Sensu em Educação da Faculdade de Educação da Universidade Federal de Goiás.

Em tempos de dominação da tecnologia altamente sofisticada, pesquisar as contribuições da literatura infantil para a formação da criança no contexto da indústria cultural constitui um imenso desafio para formadores de professores do Ensino Fundamental. Por um lado, a escola apropriou-se da literatura como um recurso diferenciado do livro didático, objetivando desenvolver a prática e o gosto da leitura na criança; por outro, essa relação entre literatura e ensino da leitura é ambivalente, visto que o livro é um recurso útil e indispensável para incentivar a criança a ter prazer na leitura, viver, sentir e sonhar o mundo imaginário das aventuras, mas também lhe possibilita questionar e compreender a realidade social. Posto isso, quando cabe à literatura cumprir sua função utilitária, por meio da legitimação da linguagem e da ideologia dominantes, necessário se faz dimensionar a preocupação em resguardar seu valor como arte, para a formação crítica da criança. 
Então, propomos discutir a contribuição da contação de histórias no espaço escolar para a construção de uma prática pedagógica reflexiva, na qual expressa a cultura e formação do professor, o aluno como sujeito e o livro literário impresso como recurso valioso para o ensino e formação cultural da criança. A investigação mostrou que a literatura infantil influencia na formação de valores na criança, tanto quando há questionamento da realidade social, como quando se reforça a ideologia dominante. A escola é um espaço educativo por excelência, e por isso seu projeto deve pautar-se em uma concepção de educação orientado para a autonomia e a emancipação visando formar crianças questionadoras, reflexivas possibilitando-as realizar experiências significativas no contexto escolar e social.

Posto isso, recorremos ao conceito de experiência de BENJAMIN (1993; 2000) e ADORNO (1995) e de estudos de pesquisadores relevantes sobre a linguagem (ZILBERMAN, 1987; BETTELHEIM, 1980; MEIRELES, 1979) para fundamentar nossa discussão pautada na relação entre educação, literatura, leitura e a criação de experiências pela criança. $\mathrm{Na}$ sequência trazemos as entrevistas que realizamos com profissionais e com alunos do Cepae, bem como nossa observação referente à atividade "Hora do Conto".

\section{Literatura e experiência}

Para Benjamin (1993), o homem moderno vai perdendo a sua história porque as impressões que ele registra em sua memória advêm da vivência construída por ações repetitivas, automatizadas, passageiras e são interrompidas pela percepção momentânea; assim, elas desaparecem e não são incorporadas à memória. De acordo com o autor " $[. .$.$] o homem conseguiu abreviar até a narrativa. Assistimos$ em nossos dias ao nascimento da short story, que se emancipou da tradição oral [...] a narrativa perfeita vem à luz do dia" BENJAMIN, 1993, p. 206). Segundo ele, a perda da tradição de narrar bem como a abreviação de histórias resultaram da criação de outros tipos de comunicação criados na sociedade moderna e capitalista, a exemplo da informação jornalística, radiofônica e televisiva. Mas, vale ressaltar que esse pensador faz a diferença entre a comunicação mediada pela narrativa e a transmitida pela informação, que, segundo ele, transmite a sua mensagem de forma aligeirada, resumida e prima pelo novo, pela notícia mundial instantânea e efêmera.

Entretanto, é preciso que o indivíduo se desloque do lugar de informante e se instale no campo da experiência, porque a informação não lhe possibilita construir a experiência, e sim a vivência. Vivência essa que extrai o seu conteúdo da mídia, da informação virtual, nos quais não há possibilidade de construção de vínculos humanos. A experiência requer que o indivíduo se relacione com o outro, que pense, duvide, modifique-se, redirecione o sentido de sua palavra, reconstrua novos significados em sua comunicação e no seu modo de viver. "Na verdade, a experiência é matéria da tradição, tanto na vida privada quanto na coletiva" (BENJAMIN, 1989, p. 105), contudo, viver o cotidiano não significa viver a experiência.

Se a arte da narrativa é hoje rara, a difusão da informação é decisivamente responsável por esse declínio [...] Cada manhã recebemos notícias de todo 
mundo. E, no entanto, somos pobres em histórias surpreendentes. A razão é que os fatos já nos chegam acompanhados de explicações. Em outras palavras: quase tudo está a serviço da informação. Metade da arte narrativa está em evitar explicações. (BENJAMIN, 1993, p. 202-203)

Para Benjamin (1989), a sociedade contemporânea nos afasta da narrativa, forma mais antiga de comunicação e, assim, convivemos com a "[...] substituição da antiga forma narrativa pela informação, e da informação pela sensação refletese a crescente atrofia da experiência"' (p. 107). A experiência de uma criança com o narrador, a qual acontece pela mediação da linguagem, possibilita-lhe imprimir em sua memória o conteúdo da história. Contar história é uma arte porque requer a expressão dos sentimentos humanos realizada pela palavra oral e por gestos. O narrador conta a história situada em seu tempo e espaço, como também as experiências construídas em viagens e aventuras. Dessa forma, ao transmitir as suas experiências e as dos outros, mediadas pela comunicação, preserva-se na memória a tradição cultural, contribuindo com a continuidade dessa tradição acrescida de novas experiências.

A leitura de um romance, ${ }^{3}$ por outro lado, se dá de forma individual e solitária, o que representa e reforça o individualismo burguês, e não a coletividade. Assim, o que se preservam na memória e, por conseguinte, na tradição são o pensamento e a atitude individual. Benjamin (1993) relacionou a arte de narrar com o trabalho artesanal que esteve presente na história milenar da humanidade. Comparou a arte de narrar com o artesanato manual (do oleiro) da sociedade antiga, época em que a experiência do feitio de uma peça artesanal foi construída em comunidade, e assim a arte de narrar também acontecia espontaneamente e em grupo; "[...] num certo sentido, uma forma artesanal de comunicação" (BENJAMIN, 1993, p. 205). Ao passo que, quando a criança visualiza uma informação virtual (a que não se realiza por meio da mediação humana), a comunicação se limita, porque não houve a interação humana entre o narrador e o ouvinte. "Contar histórias sempre foi a arte de contá-las de novo, e ela se perde quando as histórias não são mais conserváveis." (BENJAMIN, 1993, p. 205) Então, elas não são mais comunicáveis.

Desse modo, a tradição cultural, que deveria ser repassada de geração em geração pela arte de narrar, está cedendo lugar à rapidez da circulação da informação virtual e jornalística. E é de posse desse tipo de informação que o indivíduo está formando a sua mentalidade, uma racionalidade instrumental e conduzida pela sua vida prática na sociedade contemporânea. Desse modo, o visível, o excesso de informação e a redução das histórias literárias apagam a possibilidade da construção da experiência. Entretanto, a continuidade da arte de narrar é fundamental para a construção e preservação da cultura de cada época histórica. Sobre essa ideia, Benjamin afirma:

3 Segundo Candido e Castello (1991), o romance é um gênero literário da sociedade moderna que se caracteriza pelo "sentido da aventura e da criação individual", sentimentalismo, amor, "lirismo romântico". O romance contemporâneo expressa problemas sociais, ideias nacionalistas e liberais. 
Não se percebeu devidamente até agora que a relação ingênua entre o ouvinte e o narrador é dominada pelo interesse em conservar o que foi narrado [...] A memória é a mais épica de todas as faculdades [...] A reminiscência funda a cadeia da tradição, que transmite os acontecimentos de geração em geração. (BENJAMIN, 1993, p. 210-211)

Esse autor refere-se também à narrativa dos contos de fadas. Destaca a sua importância para o conhecimento da criança sobre a ambiguidade expressa nesse tipo de narrativa, por exemplo o enfrentamento de um personagem humano (uma criança) com a natureza. Para a criança vencer o medo de forças sobrenaturais é preciso agir com astúcia e arrogância. Então, “[...] o conto de fadas ensinou há muitos séculos à humanidade, e continua ensinando às crianças, que o mais aconselhável é enfrentar as forças do mundo místico com astúcia e arrogância" (BENJAMIN, 1993, p. 215). A narração de contos de fadas às crianças possibilita a elas construir experiências e pensar em sua realidade social, sobretudo quando a história lhe possibilita identificar-se com alguma atitude, um personagem, ou uma situação, sugerindo-a que pense no conflito vivido em seu cotidiano, a exemplo do medo de fantasma e de escuro e a competição entre irmãos.

Bettelheim (1980) também fala sobre a identificação com personagens dos contos para a definição de valores morais. $\mathrm{O}$ autor qualifica o conto de fadas como uma arte, porque permite que cada criança, ao ouvir ou ler uma história dessa natureza, crie diversas interpretações e significados diferentes de acordo com os seus conflitos interiores. Assim, cada criança se identifica ou não com o personagem que mais expressa as suas necessidades psicológicas, tanto no momento em que está em contato com a história, quanto ao longo de sua infância.

O conto de fadas não poderia ter seu impacto psicológico sobre a criança se não fosse primeiro e antes de tudo uma obra de arte [...] Como sucesso com toda grande arte, o significado mais profundo do conto de fadas será diferente para cada pessoa, e diferente para a mesma pessoa em vários momentos de sua vida. A criança extrairá significados diferentes do mesmo conto de fadas, dependendo de seus interesses e necessidades do momento. Tendo oportunidade, voltará ao mesmo conto quando estiver pronta a ampliar os velhos significados ou substituí-los por novos. (BETTELHEIM, 1980, p. 20-21)

Desse ponto de vista, ressaltamos a importância de se narrar a história na íntegra, sem antecipá-la com explicações de palavras julgadas pelos adultos como de difícil entendimento pelas crianças com o objetivo de facilitar a compreensão da mensagem do texto. Sendo assim, a criança poderá pensar com autonomia diante da história e de sua realidade. Entretanto, a condição essencial para que esse pensamento autônomo continue vivo é a permanência da tensão entre a imposição 
ideológica ${ }^{4}$ da indústria cultural às massas e a verdadeira realidade econômica, social e cultural.

\section{A Hora do Conto no CEPAE: a voz dos professores}

Este tópico propõe analisar as categorias elencadas previamente na ocasião das entrevistas, realizadas com dois profissionais da escola, e de outras surgidas no momento da codificação dos dados. As categorias norteadoras da pesquisa foram: educação, ideologia, indústria cultural, literatura infantil e infância. Participaram da pesquisa os profissionais que estavam envolvidos diretamente na atividade da "Hora do Conto" no período de nossa observação, a saber: a professora e contadora de histórias (P1) e o professor e escritor de literatura infantil (P2), que naquela ocasião teve um encontro com um grupo de alunos para conversarem sobre suas obras. ${ }^{566}$

No período da realização da pesquisa empírica na Biblioteca Setorial, no qual ocorreram a observação da "Hora do Conto" e a realização de entrevistas com aqueles profissionais e com uma amostragem de vinte e um alunos dois terceiros anos, percebemos o ambiente rico em cultura, especialmente com a presença dos livros literários fora da estante da biblioteca, os quais ganharam vida, voz e sentimentos todas as vezes que eram "abertos", sendo suas histórias compartilhadas pelo grupo, tanto pela contadora de histórias quanto pelas crianças. Uma vez aberto o livro, criavam-se asas para a imaginação, viagens e aventuras, passeios na floresta, enfrentamento com o lobo, lembranças do passado, etc. Por exemplo, em uma história literária, "A bela borboleta", foi retratada a ideia de liberdade pela abertura do livro: "E a borboleta explicou: - Eu não estou presa, porque cada vez que uma menina - que gosta do Gato de Botas, por exemplo - abre o livro e move as suas páginas, eu bato as minhas asas" (ZIRALDO; ZÉLIO, 1980, p. 21).

De acordo com a contadora de histórias (P1), os seus primeiros contatos com a literatura foram por meio das histórias que sua mãe lhe contava. "Eram histórias de onça, assombração. Somente aos oito anos quando fui para a escola que tive contato com o livro didático.” (P1, 2010) Meireles (1979) ilustra essa frase da contadora do seguinte modo: "[...] não há quem não possua, entre suas aquisições

4 A rigidez inexperiente do mecanismo de pensamento que domina a sociedade de massa tornase ainda mais inflexível, se isso é possível, e a própria ideologia impede que se desmascare o produto oferecido, em sua qualidade de objeto premiado para fins de controle social. "[...] Para resumir numa só frase a tendência inata da ideologia da cultura de massa, seria necessário representá-la numa paródia da frase: 'Converte-se naquilo que és', como duplicação e superratificação da situação já existente, o que destruiria toda a perspectiva de transcendência e de crítica." (ADORNO; HORKHEIMER, 1973, p. 202) "Elas podem ser verdadeiras 'em si', como o são as ideias (sic) de liberdade, humanidade e justiça, mas não verdadeiras quando têm a presunção de já estarem realizadas [...] a definição de Ideologia depende do que efetivamente atua como produto ideológico." (Idem, p.199)

5 O professor é autor de três livros literários infantis: Haja fôlego (2002); Diferente igual a todo mundo (2009); Viagens (2010). Escreve histórias infantis para o Almanaque do Jornal O Popular; entre elas, Três amigas, o triângulo (03/04/2011). 
da infância, a riqueza das tradições, recebidas por via oral. Elas precederam os livros, e muitas vezes os substituíram. Em certos casos, elas mesmas foram o conteúdo desses livros." (p. 42) Nesse sentido, a criação da imprensa, de um lado, possibilitou o registro da história oral e deu origem ao livro; com o desenvolvimento da indústria cultural, ele conquistou o seu lugar no mercado. Por outro lado, o livro ocupou espaço na convivência familiar, que antes era mediada pela narrativa oral popular. "Tempos em que a família aconchegava, criava um ambiente favorável à formação da criança. O livro vem suprir essas ausências. Tudo quanto se aprendia por ouvir contar, hoje se aprende pela leitura.” (MEIRELES, 1979, p.42) Já, agora, com a criação e inovação das tecnologias, como a internet, o computador, os jogos eletrônicos, o livro está cada vez mais se distanciando do cotidiano familiar.

A contadora define literatura infantil como aquela que lhe desperta emoção e encanto e que a sensibiliza para compartilhá-la com outras pessoas. Valoriza a qualidade gráfica e a imagem do livro, mas ressalta que é o conteúdo do livro que desperta interesse na criança pela história, e não o seu colorido somente. Em uma entrevista à Revista Escola, ${ }^{6}$ explicou: "Para mim, ninguém convence alguém a ler este ou aquele livro. O máximo que você pode fazer é passar a sua paixão por aquela leitura." (2006, p.13) A concepção de literatura da contadora relaciona-se com a sua visão de infância, porque compreende a criança como um sujeito que tem ideias e opiniões próprias que precisam ser respeitadas pelos pais e professores. "As opiniões das crianças são também importantes para os adultos. O olhar novo da criança é muito desafiador. A gente descobre o novo, é cheia de indagações. Então a criança passa a ser sujeito de direitos.” (P1, 2010)

Quando a contadora revelou os objetivos da "Hora do Conto", identificamos a contribuição dessa atividade para a formação cultural da criança para além do espaço escolar. Destacou que o contato da criança com variados tipos de recursos escritos na biblioteca bem como o ensino à criança de alguns valores (silêncio, saber ouvir e ser ouvido, respeito ao outro) contribuem para educa-la para frequentar outros espaços culturais da sociedade, como cinema, teatro e parques. Quanto à contribuição da contação para o incentivo à leitura, foram ressaltados o desenvolvimento do hábito, o gosto pela leitura de todos os tipos de produção escrita e a formação de contadores de histórias infanto-juvenis, integrando o grupo denominado por "Grupo fuxico", composto por crianças de 3..$^{\circ}$ e $4 .^{\circ}$ ano da I Fase e formado de acordo com o interesse dos alunos em contar histórias aos colegas na "Hora do Conto", nas atividades culturais da escola e na sala de aula. Entendemos que a escola desempenha um papel fundamental quando se empenha em formar contadores de histórias, visto que essa prática está se distanciando do cotidiano das famílias.

O estímulo à imaginação, à fantasia da criança, é outro objetivo revelado pela contadora. Qualificamos como nobre e formativo para a vida da criança um espaço na escola para ela imaginar e viajar com os personagens das histórias - sem ter a

6 Entrevista cedida à Gabriella Luccianni, da Revista Escola, 25 de junho a 1. ${ }^{\circ}$ de Julho de 2006.

Signos, Lajeado, ano 39, n. 1, p. 26-47, 2018. ISSN 1983-0378 
preocupação com o ensino das regras gramaticais e sem interromper a história para explicar significados das palavras - já que o mundo virtual predomina na maioria dos espaços sociais. "[...] não se pode pensar numa infância a começar logo com a gramática e retórica: narrativas orais cercaram a criança da antiguidade, como as de hoje. Mitos, fábulas, lendas." (MEIRELES, 1979, p. 46) Para Bettelheim (1980), a criança necessita alimentar o seu pensamento fantasiando e imaginado, à sua maneira e de acordo com suas necessidades, os acontecimentos da vida cotidiana, para formar uma personalidade forte, e os contos de fadas, principalmente, possibilitam esse exercício interior.

[...] nossas fantasias são recursos naturais que fornecem e moldam esta matéria-prima [o inconsciente], tornando-a útil para as tarefas de construção da personalidade que cabem ao ego. Se somos privados desta fonte natural, a vida fica limitada; sem fantasias para nos dar esperanças, não temos forças para enfrentar as adversidades da vida. A infância é a época em que estas fantasias precisam der nutridas. (BETTELHEIM, 1980, p.152)

Nesse sentido, partimos da premissa de que a literatura infantil contribui com a formação da criança desde os seus primeiros contatos com as histórias orais no seio da família e, em seguida, na escola. Ressaltamos que a valoração atribuída pela contadora, quando seleciona as histórias, expressa a ideologia dominante do sistema no qual se formou. As obras literárias também retratam traços dessa ideologia. "Sabemos que nenhum texto para crianças é neutro ou inócuo: todos arrastam consigo, com consciência ou não do autor, ideias, valores, padrões estéticos." (VELOSO, 1994, p. 26) Desse modo, a leitura prévia e a avaliação dos livros para trabalhar com as crianças são fundamentais para que se efetivem os propósitos da "Hora do Conto". Ressaltamos que a contadora apontou cinco critérios utilizados para a seleção dos livros: 1) livros que lhe provocam emoção e encantamento e despertam vontade de compartilhá-los com os outros; 2) autores que se conhecem por meio da pesquisa de suas biografias e produções; 3) temas interdisciplinares sugeridos no planejamento coletivo da escola; 4) observação do interesse do aluno em pegar o livro para empréstimo; 5) autores que retratam o cotidiano dos alunos e se preocupam a qualidade gráfica.

Com esses critérios, a contadora (P1) revelou uma relação entre literatura, emoção e o desejo de compartilhar a história lida com os outros. Percebemos que literatura relaciona-se com sentimento, com aspectos subjetivos do sujeito. "A minha responsabilidade como contadora de histórias é dizer que o texto em questão é bom, é poético, é maravilhoso, mas também que essa contação, de maneira alguma, exclui o livro." (LANDIVAR, 2006) Assim, acreditamos que a literatura que desperta sentimentos, que atinge o íntimo do pensamento, seja no imaginário seja no real, possui qualidade, e é isso que atribui estatuto à literatura infantil.

Um bom texto para crianças tem que inculcar nelas confiança, coragem e vontade de comunicar com os outros [...] Ideias, sentimentos, emoções, experiências só constituem matéria prima de uma obra literária quando transformados em linguagem verbal. (VELOSO, 1994, p.28) 
O critério 3, temas interdisciplinares, revelou de forma explícita a relação entre literatura e ensino, na qual se propõe destacar temas comuns entre as diversas áreas no processo ensino-aprendizagem das crianças. Então, podemos dizer que estamos diante da didatização da literatura criada pela escola, fenômeno que gerou divergências, conforme alguns críticos literários. ${ }^{7} \mathrm{O}$ trabalho intencional da literatura no ensino da leitura junto a outras áreas do conhecimento tornou-se uma prática frequente nas escolas do Ensino Fundamental, que é a apropriação da literatura pela pedagogia, que resultou em seu aspecto utilitário e que, em razão disso, comprometeu a abordagem da literatura como arte. Zilberman (1987) questionou esse modo de aproximação da pedagogia com a literatura infantil: "[...] lhe causa grandes prejuízos: não é aceita como arte, por ter uma finalidade pragmática; e a presença deste objetivo didático faz com que ela participe de uma atividade comprometida com a dominação da criança" (p. 14). Questiona-se, portanto, se a apropriação da literatura para o ensino da leitura e de outros conteúdos pode auxiliar no desenvolvimento do gosto e hábito da leitura na criança, ainda que seja valorizada a intenção de trabalhar as normas gramaticais e os valores. "Eleito o tipo preferencial de leitura na escola, a literatura assume uma significação que se confunde, muitas vezes, com um modelo de transmissão de valores de natureza autoritária e normativa." (ZILBERMAN, 1988, p. 116)

O contador, quando destaca os valores retratados nos textos literários, transmitem às crianças a ideologia do sistema no qual se insere, mas esses devem também ser questionados, para não se incorrer no que Adorno denominou adaptação, impeditivo para a emancipação. "A literatura infantil, por sua vez, é outro dos instrumentos que têm servido à multiplicação da norma em vigor [...] o adulto intervém na realidade imaginária, usando-a para incutir sua ideologia." (ZILBERMAN, 1987, p. 20) Podemos aqui tomar como exemplo desse modo reduzido de se relacionar com a literatura o interesse em ilustrar a linguagem dos livros didáticos por meio da inserção de textos literários, o que se justificou, a exemplo da cartilha Caminho suave, pelo fato de alguns livros de literatura infantil apresentarem uma linguagem resumida em letras, famílias silábicas, frases e pequenos "textos" fragmentados, desprovidos de sentido.

No critério 4, considera-se o interesse da criança pelo livro. A contadora expressou a sua coerência quando nos disse, anteriormente, que a criança tem opinião própria e que deve ser ouvida pelo adulto; assim, demonstrou que parte também do conhecimento da criança para selecionar o livro. Afinal, não é a criança que define o que é a literatura infantil? Também o último critério, livros que retratam o cotidiano dos alunos e que tenham qualidade gráfica, leva-nos a pensar que a contadora se preocupa em discutir com as crianças temáticas que suscitam seus conflitos psicológicos, existentes no decorrer da formação de sua personalidade, gerados em suas relações interpessoais cotidianas com irmãos, primos, pais, colegas e professores.

7 Coelho (1997); Meireles (1979); Zilberman (1987; 1988); Machado (2001); Veloso (1994). 
Bettelheim (1980), quando analisa o conto "A Guardadora de Gansos", escrito pelos irmãos Grimm, explica:

O conto de fadas sugere que não é tanto os fatos marcantes que contam, mas um desenvolvimento interno que deve ocorrer para que o herói conquiste uma verdadeira autonomia. Tornar-se independente e transcender a infância requer um desenvolvimento da personalidade, e não apenas ser melhor numa tarefa específica, ou batalhar com dificuldades externas. (BET'TELHEIM, 1980, p. 175)

Essa intenção da contadora em trabalhar aspectos reais da vida da criança contribui para a formação do pensamento crítico e da autonomia desta, entretanto essa abordagem deve colaborar para que a criança não se limite a compreender e a se identificar imediatamente com a realidade na qual se insere; é preciso também transcender esse momento para que ela construa, junto a seus grupos de convivência, de maneira emancipatória, possibilidades de outras formas de educação. Nessa direção, “[...] a desbarbarização da humanidade é o pressuposto imediato da sobrevivência. Este deve ser o objetivo da escola, por mais restritos que sejam seu alcance e suas possibilidades" (ADORNO, 1995, p.117).

O professor e escritor de literatura infantil (P2) relacionou a sua concepção de infância com a inspiração para escrever sobre literatura implicando-se com a psicanálise. "A psicanálise nos ensina que o infantil permanece dentro da gente, que nos constitui como adulto." (P2, 2011) Em sua atuação como artista demonstrou essa ideia quando disse que brinca com as palavras como na poesia, na música, na peça de teatro, enfim, destacou que, como adulto, em suas atividades profissionais, sempre houve um tom lúdico. Sobre a influência da história de vida na criação literária, o professor relatou que "[...] toda história tem a ver com a nossa história. Toda a história de nossa vida começa na infância, que é a base” (P2, 2011). Essa ideia nos remete à discussão de Adorno (2008) sobre a constância do todo e da parte na criação da obra literária. "Uma corrente subterrânea coletiva é o fundamento de toda lírica individual [...] pois somente ela faz da linguagem o meio em que o sujeito se torna mais do que apenas sujeito.” (p. 77) Assim, a obra literária resulta dessa corrente social, que é a estrutura e a inspiração individual do escritor. O professor destacou ainda sua admiração pela palavra, por ela expressar "sensioralidade", sensações, prazer e som. "O homem, e muito em particular a criança, forma a sua consciência do mundo através da palavra, suporte de cultura e elemento criador." (VELOSO, 1994, p. 19)

Sobre a diferença entre a contação de história na "Hora do Conto", na sala de aula e na família, o professor (P2) disse que todos esses espaços e momentos são importantes para desenvolver o interesse e o gosto na criança pela leitura. Entretanto, ressaltou que esse interesse é condicional à forma como o contador narra uma história. "Dependendo do contador, a criança gosta ou não gosta. Pode estimular o leitor e pode afastar o leitor também do livro." (P2, 2011) Nesse aspecto, pensamos que a atividade literária como contação, por propiciar a comunicação entre o narrador e o ouvinte, contribui com a formação cultural mais 
ampla da criança, principalmente se a comparamos ao tom pedagógico atribuído pela professora em sala.

O texto não pode continuar a ser mero pretexto para aprendizagens de ordem cognitiva, confundindo a dimensão estética e afectiva da literatura com a funcionalidade didactica do livro informativo ou para-informativo [...] o acesso ao sentido é indispensável para que o leitor possa ligar as duas histórias: a que está contida no livro e a sua. O professor não deverá estar preocupado com o significado de uma ou outra palavra eventualmente desconhecida, mas com as condições de interpretação do texto. (VELOSO, 1994, p. 672)

Para o professor (P2), a contação de histórias pelos pais é importante para a relação afetiva da criança, porque "a voz passa o afeto, o carinho" (2011). Mas lembrou que as pessoas não têm tempo para contar histórias e que a escola cumpre esse papel. Assim, dentre as instituições sociais como a família e a escola que educam as crianças, a escola tem-se revelado como um espaço educativo que ainda se utiliza da literatura infantil em diversas atividades na formação de seus alunos, conforme demonstramos nesse trabalho.

\section{A "Hora do Conto" na biblioteca: a voz dos alunos}

A atividade "Hora do Conto" é uma proposta que integra as atividades culturais da biblioteca e do Cepae, desde 1993. A biblioteca conta com a coordenadora, duas funcionárias e dois estagiários da UFG, um do curso de Biblioteconomia e outro do curso de Letras. Esses estagiários contribuem com essa atividade orientando os alunos na escolha de livros, no empréstimo e na sua devolução. O seu principal objetivo foi o incentivo à prática de leitura e à formação de contadores de histórias. No horário oficial da escola estava previsto o dia da semana em que cada turma participaria dessa atividade. No segundo semestre do ano de 2010, uma professora do Cepae e integrante do "Grupo Gwaya - contadores de histórias" desenvolveu a atividade de Contação de História para os alunos do $1 .^{\circ}$ ao $4 .^{\circ}$ ano da I Fase.

A realização das entrevistas com vinte e um aluno (21) do $3 .^{\circ}$ ano pautou-se em um roteiro (Apêndice) expresso nos tópicos: site de leitura na internet; diferença entre a leitura de histórias no computador (internet) e a feita no livro; histórias e personagens preferidas das crianças; relação entre a história ouvida ou lida pela contadora com a vida das crianças; diferença entre o livro didático e o livro literário. Do total de 43 (quarenta e três) histórias conhecidas pelos alunos, no contexto escolar e familiar, estes relacionaram cinco com que eles mais se identificaram, sucessivamente: "Bruxa Onilda vai à Nova Iorque"; "A centopeia que sonhava;" "Os três porquinhos"; "Anúncio no jornal" e "Quem tem medo de mostro".

A observação da "Hora do Conto" teve o propósito de investigar se as crianças se identificavam com algum conteúdo ou personagem da história contada. As crianças leram e memorizaram histórias e poesias em casa e as contaram aos colegas na "Hora do Conto". A partir dessa questão constatamos que, dentre as 29 histórias contadas pela contadora e pelos alunos do $3^{\circ}$ ano, as crianças identificaramse com seis: "O cabelo de Lelê"; "Rabo peludo, gato pelado" ; "Anúncio no Jornal”, 
"A bela borboleta", "O videotinha" (letra de música); e "Capitão sem fim" (poesia). $\mathrm{Na}$ ocasião da pesquisa, observamos 75 sessões de contação de histórias destinadas aos alunos do $1 .^{\circ}$ e do $3 .^{\circ}$ ano. Cada uma dessas sessões, em horários diferentes, teve a duração de 45 minutos. Então, foram observadas 56 horas e 25 minutos dessa atividade. Durante as observações identificamos uma rotina constituída por seis momentos: 1) discussão sobre a importância da leitura do livro literário para o desenvolvimento da prática de leitura; 2) apresentação do livro; 3) contação da história; 4) momento do "fuxico" ou "cochicho" entre os alunos; 5) discussão coletiva sobre a história; 6) devolução e empréstimo de livros.

O livro "O cabelo de Lelê" conta a história de uma menina negra que, com o tempo, vai descobrindo a sua origem africana. Os seus cabelos cacheados e volumosos a incomodam, causando-lhe insatisfação. Então, ela busca, através do livro "Países Africano", as suas raízes culturais. A partir desse conhecimento, Lelê "descobre a beleza de ser o que é", se aceita e descobre a origem de sua identidade. Assim, a sua diferença não é motivo para o outro não aceitá-la; ao contrário, "encontra o menino a quem se avizinha". Desse modo, percebe que os seus cachinhos são parte de sua descendência africana. No final, as ilustrações revelam os vários tipos de penteados que podem ser feitos com o cabelo de Lelê (em forma de trancinhas, com adornos, etc.).

A história citada foi contada aos alunos do $.1^{\circ}$ ano. Quando a professora começou a apresentar a história, sem mostrar o livro, uma criança levantou a mão e disse: "A Lelê tem os olhos azuis? Que cor é o cabelo dela? A professora não respondeu e pediu aos alunos para se organizarem em dupla, ficando um de frente para o outro, se olhando e observando o rosto de cada um. A contadora expôs a questão aos alunos: "O que você gosta do que vê? Após essa atividade, uma aluna revelou: "Eu achei bonito o cabelo dela. Eu queria ter um cabelo loiro também. Depois da contação dessa história, houve o momento da discussão entre todos. Uma aluna disse: "Eu tenho cacho. Não gosto do meu cabelo. Gostaria que ele fosse liso. Não gosto do meu rosto". A fala dessas alunas revelou a não aceitação da nossa descendência africana, isto é, a falta de identificação com o seu cabelo preto e cacheado. Crochík (2011) nos ajuda a pensar sobre essas falas quando discute o preconceito como elemento que se constitui no processo de socialização do indivíduo, desde a infância, no qual a cultura vai-se formando de acordo com os valores dominantes de cada época histórica. Assim, para o autor, “[...] se o preconceito não é inato, a criança pode, de fato, perceber que o outro é diferente dela, sem que isso impeça o seu relacionamento com ele" (p. 17). Nesse sentido, a escola tem um papel fundamental na discussão dos preconceitos revelados pelos alunos no espaço escolar. Segundo o autor, o preconceito pode se desenvolver, ou não, então há possibilidade de impedir que ele continue presente no pensamento das pessoas.

O que leva o indivíduo a desenvolver preconceitos, ou não, é a possibilidade de ter experiências e refletir sobre si mesmo e sobre os outros nas relações sociais, facilitadas ou dificultadas pelas diversas instâncias sociais, presentes no processo de socialização. (CROHÍK, 2011, p. 19) 
Sobre a necessidade de se ter experiência, Adorno (1995a) aponta que uma das alternativas para se sair da condição de sujeito adaptado e acomodado ao sistema dominante é a criação de experiências contrárias às do passado nazista (é salutar lembrar, nesse momento, o preconceito dos alemães nazistas com todas as raças diferentes da sua, especificamente com os judeus, o qual fez parte da cultura alemã e estendeu-se às outras culturas). Essas experiências devem ser construídas pela reflexão da realidade social, pelo questionamento da própria razão que rege esse sujeito e pela consciência da criança que está sendo formada. Segundo Coêlho (2009), educar é instigar o pensamento, provocar a dúvida e a inteligência, formar leitores, enfim, é a possibilidade de criação de uma humanidade mais justa. Então, se a escola educar a criança com base nesses princípios, as possibilidades de compreensão das contradições sociais se ampliam. Por certo, a educação tem a função ambivalente, de um lado a criança deve-se integrar continuamente à cultura na qual vive, adaptando-se a ela, porque precisa conhecer, socializar-se com o conhecimento, valores e normas construídos no percurso da história, por outro lado, a educação deve, também, cumprir o seu papel de orientar os indivíduos na direção contrária a violência física e psicológica (ADORNO, 1995).

$\mathrm{Na}$ entrevista realizada com os alunos do $3 .^{\circ}$ ano, a questão do preconceito também se manifestou. Três alunos, ao citarem as histórias com as quais se identificaram, revelaram questões ligadas ao preconceito. Dois alunos citaram o livro "Morango sardento", que foi trabalhado em sala de aula e levado para ser lido em casa. A história narra a vergonha que uma criança de sete anos tinha de seus cabelos ruivos e de sua pele coberta de sardas. $\mathrm{O}$ aluno (A7) nos disse que se lembrou de um vizinho que era chamado de gordinho: "[...] colocou apelido nele de lasanha. Esse apelido é muito constrangedor, gozador." A aluna (A8) também referiu-se a essa questão e demonstrou ter consciência, ao dizer: "não precisa ter vergonha do que a gente é por dentro e por fora", e criticou sua amiga de outra escola que a chamou de "baleia assassina, gorda demais". Outra aluna (A13), ao citar o livro "Todo mundo é diferente", revelou que não convive bem com os seus cabelos: "Eu queria parecer com todo mundo, com a F, ela tem muitos amigos, é legal e é bonita também. Não gosto do meu cabelo, porque é enrolado e muito difícil de pentear."

As falas dos alunos reforçam a ideia de que os indivíduos agem e pensam de acordo com os valores construídos em cada cultura, porque "[...] as ideias sobre o objeto do preconceito não surgem do nada, mas da própria cultura" (CROCHÍK, 2011, p. 14).

Nesse sentido, a escola em que realizamos a nossa pesquisa representa a cultura brasileira. Para o autor acima, o agir de forma imediata diante de alguém, sem reconhecimento das diferenças interpessoais e sem reflexão, reforça o preconceito. E, segundo Adorno e Horkheimer (1991), a ideologia capitalista como organizadora

8 A criança pode ter-se lembrado do filme americano "Orca - A baleia assassina", produzido em 1977 por Dino De Laurentiis. 
do mundo "[...] converteu-se a si mesma imediatamente em sua própria ideologia. Ela exerce uma pressão tão imensa sobre as pessoas, que supera a educação." (p.143) De acordo com este último, a ideologia representa a própria sociedade; sustenta e legitima o preconceito, visto que a atitude preconceituosa de uma criança em relação a si e ao outro, faz parte, com maior ou menor frequência, da maioria dos setores e instituições sociais, porque sua referência é o valor padronizado. Por exemplo, o cabelo liso e loiro é apreciado pela maioria. Desse modo, mesmo com limitações, acreditamos que a literatura pode mediar a formação crítica da criança, oportunizando a ela condições de revelar os seus valores e seus conflitos de identificação em relação ao outro, ao diferente, e contribuindo para a formação de sua própria identidade e de sua autonomia. No entanto, a manifestação dos valores pelas crianças requer uma discussão política com toda a turma, para oportunizar que elas pensem sobre as diferenças; caso contrário, a educação reforça a ideologia dominante.

O livro "Anúncio no jornal" retrata a história de uma criança que sentia saudade da convivência e dos ensinamentos de sua avó, que falecera, o que a fez ter a ideia de escrever um anúncio no jornal, sob forma de carta, para se comunicar com ela: "vó, tô botando este anúncio no jornal, porque tem um bichinho, aqui dentro de mim, que não me deixa em paz. Papai falou que era saudade" (SIGUEMOTO, 1996, p. 4). A contadora iniciou a atividade com as duas turmas do $3 .^{\circ}$ ano indagando aos alunos: o que tem no jornal? Alguns alunos responderam:

Tem o Ti-ti-ti, parece uma comédia. Tem o nome dos filmes que vão passar no cinema. Empregos, casas, condomínio. - Jogo dos sete erros, piadas, anúncio. - Filme de ação, o que vai passar na televisão. - Informação da cidade. - Palavras cruzadas, coisas dos famosos. - Política, quando a Dilma ganhou, quando está aumentando a chance de um candidato ganhar.

As falas dos alunos revelaram quais informações do jornal lhes interessavam. Percebemos que parte do conteúdo apontado relacionou-se a programas televisivos e a atividades de diversão, como palavra-cruzada, jogo dos sete erros e piadas, os quais são contemplados nas atividades didáticas da escola.

No decorrer da contação da história, todos os alunos se concentraram acompanhando atentamente, do início ao fim, a fala e os gestos da contadora. No momento da discussão a maioria dos alunos relacionaram o conteúdo da história com a sua vida e disseram:

O jornal falou da avó que já morreu. Lembrei da minha avó. Ela morreu quase desse mesmo jeito. - Também pensei no avô. Meu avô também morreu. - Lembrei da minha avó. Ela contava a vida dela, piada, histórias. - Tenho lembranças boas da avó e queria que ela voltasse. - Vamos parar de falar de morte, a gente tem um futuro grande pela frente (Alunos Cepae, 2010).

Nas entrevistas, três alunos se lembraram da história "Anúncio no jornal" e todos demonstraram, em suas falas, ter uma identificação com os avós. "Não conheci meu avô por parte de pai. Eu sonhei com ele, imaginando como ele era." (A8) "As vezes ela é legal, quando vai dormir no mesmo quarto e ela conta história 
para mim." (A13) "Lembro do meu avô, ele brincava com a gente, era o que eu mais gostava." (A15) Notamos que o conteúdo dessa história instigou as crianças a pensarem sobre a sua convivência familiar. Então, continuamos a ressaltar a importância de contar história às crianças na escola, destacando a importância de se garantir a fala das crianças para que expressem a sua interpretação e o sentido que o texto teve para a vida delas.

O livro "A bela borboleta" conta a história de uma borboleta que fica presa dentro de um livro quando ele permanece fechado. Mas, ela se liberta abrindo as asas e voando num certo momento: "Eu não estou presa, porque cada vez que uma menina [...] abre este livro e move as suas páginas, eu bato as asas!" (ZIRALDO; ZÉLIO, 1980, p. 21) No momento em que a contadora abriu a página que representava as asas abertas e coloridas da borboleta, houve espanto e encanto por parte de todos os alunos. Dentre os cinco alunos que se manifestaram sobre a história, três a relacionaram com sua vida: "Na chácara, botei uma lagarta na caixa e no outro dia virou uma borboleta." "Era pequeno e não sabia que coró e lagarta virava borboleta." "Estava com a unha azul aí a borboleta pousou na minha mão." Outros dois meninos falaram sobre a história: "A borboleta não estava presa, porque quando abria o livro ela voava." "Ela saía para outro livro." $\mathrm{Na}$ entrevista, uma criança disse que se lembrava de várias borboletas que ficavam em seu jardim. Assim, outra vez, percebemos que a história propiciou que a maioria das crianças relaciona esse o conteúdo da história com a sua vida.

$\mathrm{Na}$ "Hora do Conto", houve também a declamação de poesias. A contadora recitou a poesia "O capitão sem fim" e, no mesmo dia, uma aluna do $3 .^{\circ}$ ano declamou outra poesia de sua própria autoria, "Viajar pela leitura".

Viajar pela leitura sem rumo; Sem intenção; Só para viver a aventura; E ter um livro nas mãos; É uma pena que só sabe disso; Quem sabe ler, experimente; Assim mesmo sem compreender; Você vai entender; Mergulhe de cabeça na sua imaginação. (Aluna do $3 .^{\circ}$ ano, 2010)

A poesia da criança expressa sua concepção de leitura literária, indicando que essa leitura a leva à imaginação e ao prazer de ler. A poesia "O capitão sem fim" narra a história de um capitão que está dentro do navio que está no mar que não tem fim. Ao descer para o porão, encontra uma caixa "[...] que tem guardado o anel de um mágico do Japão e no jade do anel existe, escrita à mão, a história de um mar, de um mar com seu capitão que está em um navio [...] (CAPARELLI, 2006). $\mathrm{Na}$ hora da discussão, cinco crianças manifestaram opinião sobre a história. Três crianças relacionaram a história com sua vida quando disseram: "A história nunca acaba, por isso que é capitão sem fim. Quando fui para a praia tinha mar, navio, capitão." "Fui em um lugar que tinha muita pedra, mar". "Eu nunca pisei na areia da praia, eu tenho vontade de ir." Essa história instigou também a imaginação de outras crianças: "Legal, eu vi o que estava na poesia. Fui imaginando o mar, o navio, a caixinha, o anel." "Eu fui imaginado uma caixa vermelha com anéis de pérola."

$\mathrm{Na}$ "Hora do Conto" foi trabalhada também a letra de música "Videotinha", escrita em forma de poesia e que narra a história de crianças que só ficavam em 
frente da televisão jogando videogame. Não conversavam, nem brincavam e nem liam, por isso "[...] sua cara foi tomando o formato de telinha..." (BEDRAN, 2008). A contadora leu a letra da música para as crianças e, em seguida, perguntou a elas: "Por que li este texto para vocês?" Dois alunos responderam: "Porque somos leitores. Vamos para a biblioteca pegar livros"; "Pra ler, a gente não quer saber de ler". Percebemos que, em todas as falas, as crianças se reportaram à leitura, o que indica que elas compreenderam a polêmica proposta pela autora entre a prática de leitura e a do jogo virtual. O conteúdo da poesia provoca questionamentos sobre a ocupação do tempo livre da criança com o jogo eletrônico. Em decorrência disso, destaca aspectos que comprometem as relações sociais e a formação humana da criança, a exemplo de seu isolamento de amigos e distanciamento das brincadeiras e da leitura. A comparação da feição, do rosto da criança, com o "formato de telinha" sintetiza simbolicamente os efeitos que o vício cria na criança quando ela fica por muito tempo diante de uma tela virtual, levando-a à deformação. Esse texto da autora nos remete a Benjamin (2000), quando se referiu à comunicação entre olhares. Quem fita o olhar ao outro necessita ser correspondido, isto é, deseja que o outro responda a seu olhar. Mas, o olhar da criança na telinha compromete o seu retorno e, se assim for, a comunicação não acontece, porque não há linguagem para mediá-la.

A contadora de histórias, ao trazer a letra da música "O videotinha" para trabalhar na "Hora do Conto", criou uma situação importante de debate sobre a realidade virtual produzida pela indústria cultural. O que está em questão é a nossa preocupação com o processo de identificação pelo qual a criança passa no período escolar, já que nesse processo os objetos com os quais se relaciona e se identifica, ou não, decorrem da cultura na qual ela vive. E essa é a cultura da tecnologia representada nos jogos eletrônicos e na internet, que participa do tempo livre da maioria dessas crianças. A identificação da criança com a realidade virtual é imediata e irrefletida, a ponto de idealizar tanto a realidade quanto a própria criança, resultando na dependência e tornando-se impeditiva para que se pense essa realidade; enfim, limitando-se à adaptação. Partindo da premissa de que a identificação extrema da criança com o objeto ou com o outro é um processo que gera a idealização de ambos, assim como dificulta que a criança separe o mundo imaginário do mundo real e provoca nela uma confusão entre a realidade e o virtual, Zanolla afirma:

Ao pesquisar os jogos na atualidade, é possível identificar essa indiferenciação da realidade com o virtual. Nos jogos, as crianças imitam, por meio do brincar, comportamentos e atividades exercidas pelos adultos. O brinquedo tem um significado especial par a criança e o adulto, nessa luta do imaginário versus real. (ZANOLLA, 2010, p. 90)

A ideologia da indústria cultural, quando cria o consumidor para os seus produtos virtuais pela comunicação massificada, cumpre o papel de encobrir com o véu a possibilidade de a criança vivenciar a imaginação. Essa identificação e idealização podem conduzi-la a uma atitude de indiferença e de frieza para com o outro, visto que essa realidade é vazia de sentido, porque não há a presença do 
afeto humano. De acordo com Adorno (1995a), a educação contrária à barbárie, voltada à emancipação, requer, necessariamente, a formação da identidade da criança pautada nas relações de afeto, amor e carinho. Ele diz que a tentativa de reverter a personalidade de um indivíduo que praticou e que sofreu violência no período nazista é impossível, porque, "[...] sobretudo, não é possível mobilizar para o calor humano pais que são, eles próprios, produtos desta sociedade, cujas marcas ostentam" (p.137). É por esse motivo que o autor indica uma educação para a emancipação desde a primeira infância.

Nesse sentido, a escola e a família são as principais instituições que devem orientar as crianças nas escolhas de seus brinquedos e de livros literários formativos, os quais direcionem à autonomia, emancipação, reflexão da realidade e da criação de novas experiências. E essa orientação é política, visto que os adultos que formam a criança carecem de ter consciência acerca de qual educação querem para o presente e o futuro.

Essa relação da criança com o mundo virtual também faz parte da cultura escolar. Em uma sessão de contação de histórias, a contadora apresentou e distribuiu aos alunos, por escrito, a relação de dez sites de leitura ${ }^{9}$ postados na internet. Em seguida todos foram para a sala de computação para acessá-los. $\mathrm{Na}$ entrevista, quisemos saber se os alunos percebiam a diferença entre a leitura da história feita no livro e a lida na internet. Dentre os 16 alunos que disseram acessar sites de leitura na internet, cinco se manifestaram sobre essa diferença:

O livro vai ajudar as pessoas a ter a leitura melhor. - É diferente ver o livro no computador e pegar o livro com as próprias mãos. - $\mathrm{Na}$ internet você vê, mas não tem noção de esfolhear o livro. Sente prazer ao tocar no livro. Eu viajo no livro imaginando tudo dele. - Pegando o livro eu imagino no mundo dos livros. Quando toco no livro é um milagre. Fico chateado quando esqueço o livro para devolver. - Não gosto de acessar a internet para ler livros. Eu gosto de ler o livro. O livro é a história mesmo que o autor escreveu com detalhes. (Falas de cinco alunos, Cepae, 2010)

Diante das falas dos alunos, notamos que eles percebem a diferença entre a leitura no livro e na internet. Quando uma criança diz que "o livro é a história mesmo", indica-nos que, por gostar de manusear o livro literário, ela separa a realidade do virtual. Provavelmente, se não se identificasse com o livro, não saberia nos dizer com tanta clareza e segurança essa diferença. Em duas falas percebemos que o livro possibilita à criança imaginar e viajar na história lida. Em nenhuma fala a criança expressou preferência e afeição em ler a história literária pelo site de leitura. Então, qual o sentido de repassar esses sites de leitura para as crianças na "Hora do Conto", como atividade na escola, visto que a maioria dos alunos tem internet em

9 www.doceletra.com.br; www.angela-lago.com.br; www.on.br/site_brincando; www.monica.com. br/index.htm; www.kidleitura.com; www.contandohistoria.com; www.maquinadequadrinhos. com.br; www.sitedepoesias.com;chc.cienciahoje.uol.com.br; www.origami-club.com/en/ (Sites de leitura, Cepae, 2010) 
casa e esse momento de contação pode ser um espaço para que as crianças pensem a realidade e criem experiências?

A seguir ressaltamos as histórias citadas pelas crianças, suas opiniões e temáticas construídas a partir da codificação dos dados. No decorrer das entrevistas, em um total de 21, elas citaram mais de uma história "preferida", resultando em 27 histórias e 48 opiniões. Dentre essas crianças, 14 revelaram identificar-se com mais de uma história. A análise dos dados indicou que alguns temas predominaram: projeção, ${ }^{10}$ (relação história literária e vida): 62,50\%; identificação (desejo de estar no lugar do outro): 39,58\%; ideologia (valores sócio-culturais dominantes): 35,49\%. Destacamos para análise as quatro histórias com as quais grande parte das crianças se identificou: "Bruxa Onilda vai à Nova Iorque" (23,33\%); "A centopeia que sonhava" (19,00\%); "Os três porquinhos" (8,40\%); "Anúncio no jornal" e "Quem tem medo de monstro" (6,30\%).

A primeira retrata a história de uma bruxa que vai expor os seus produtos de bruxaria na Feira Internacional de Bruxologia em Ciências Ocultíssimas na cidade de Nova Iorque. O seu principal objetivo é tornar-se rica e famosa. Mas, ao experimentar a sua fórmula, houve falhas e, então, ela se decepcionou e perdeu a esperança de conquistar o sucesso. As temáticas identificadas nas falas das crianças foram ideologia, identificação e projeção.

Ao pensarmos na ideologia, no contexto de nossa pesquisa, remetemo-nos, necessariamente, ao consumo dos produtos da indústria cultural e à identificação da criança com algum deles em seu cotidiano. Podemos voltar aqui à afirmação de Adorno (1995): “[...] a organização do mundo converteu-se a si mesma imediatamente em sua própria ideologia. Ela exerce uma pressão tão imensa sobre as pessoas, que supera toda a educação" (p.143). A ideologia dominante na família e na escola aparece em algumas falas das crianças: "Gostaria de viajar para Nova Iorque. Meu primo foi para Disney e trouxe uma boneca para mim, da Bela Adormecida." - "Queria conhecer Nova Iorque". Partindo sempre do pressuposto de que a literatura participa da formação cultural da criança e contribui com a constituição de seu pensamento crítico ou não, a escolha da história pelo contador, ou professor, é política e ideológica, portanto contraditória. Outras crianças se identificaram com aspectos físicos e objetos mágicos da bruxa: "Quero parecer com a bruxa, eu quero ter o olho dela. O chapéu dela é engraçado." - "Gostaria de ser a vassoura da bruxa, porque queria voar com a Bruxa Onilda para a floresta, shopping, supermercado."

Por outro lado, a história "A centopeia que sonhava" trata de uma lagarta que sonhava em realizar diversas aventuras, como voar, nadar, cantar, tocar flauta e

10 Segundo Laplanche e Pontalis (1986), “[...] projeção é a operação pela qual o indivíduo expulsa de si e localiza no outro, pessoa ou coisa, qualidades, sentimentos, desejos e mesmo 'objetos', que ele desdenha ou recusa em si. É uma exteriorização de um processo interno; o indivíduo lança para fora de si aquilo que não quer e reencontra-o ulteriormente no mundo exterior" (cf. p.478 e p. 484). 
pular de galho em galho. Mas, só as conseguiria com a ajuda de outros animais. A maioria das crianças revelou o desejo de aprender a nadar, seguido de voar, cantar, vontade de comer muito e de adquirir um notebook, conforme demonstraram em suas falas: "Meu sonho é nadar." - "Queria saber nadar igual a um peixe." -"Eu queria ser um peixe para nadar e perder a respiração." - "Eu me lembro quando fui aprender a nadar." Outras crianças revelaram seus sonhos ou fantasias do seguinte modo: "Eu queria ser um tucano para voar pelo mundo." - " Eu queria voar para ver tudo, sentir o vento". Nota-se que o desejo de aprender a nadar diz de uma realidade particular, ao passo que o interesse em conhecer o mundo e de ver tudo refere-se ao universal, ao sonho de sair de seu lugar (cotidiano) e ir além dele.

A lembrança das histórias preferidas pelas crianças revelou uma identificação com sua história de vida e com a realidade de sua estrutura familiar. Dentre as quatro crianças que se identificaram com a história "Os três porquinhos", duas compararam os diferentes tipos das casas construídas pelos porquinhos com suas casas e disseram: "Conta a história do passado da gente. Quando morava na casa de lona, de madeira e depois de tijolo. Parece com a história dos três porquinhos." (A4, 2010) - "A minha casa é de tijolo. Acompanhei a construção da minha casa. Adoro minha casa é tudo para mim." (A21, 2010)

De acordo com Betthelheim (1980), “as casas que os três porquinhos constroem são simbólicas do progresso do homem na história: de uma choça desajeitada para uma casa de madeira, finalmente para uma casa de tijolos" (p.53). As identificações das crianças possibilitam revelar o "princípio de realidade", ${ }^{11}$ ao trazer para as suas vidas esse aspecto da história. Essa ideia é corroborada quando o autor diz: "só o mais velho dos porquinhos aprendeu a viver de acordo com o princípio da realidade; ele é capaz de adiar seu desejo de brincar [...]" (BETTHELHEIM, 1980, p. 54).

Para uma outra criança, o medo do lobo pelos porquinhos a fez lembrar um fato ocorrido, relacionado ao medo que sentiu ao se deparar com policiais armados: "Parou (sic) umas pessoas que estavam com asmas, aí eu e meus colegas se escondeu." (A16, 2010) Ainda, outra criança se lembrou da história pela fantasia: "Gosto de ser uma porquinha e construir uma casa na floresta e matar o lobo mal." (A5) Conforme as falas das crianças, constatamos que, nas três primeiras, o sentido atribuído à história originou-se de fatos de seu cotidiano e que a mesma história pode despertar diferentes interpretações, se oportunizado à criança o direito de expressar-se sobre a narrativa.

A história "Quem tem medo de monstro" fala de um menino que vai passar o inverno no chalé de sua avó e começa a ouvir ruídos do lado de fora. Então, inicia-se o seu medo fantasioso pelo monstro, que é representado pelo vulto em forma de fantasma. E, no final, o personagem infantil diz: "Fiquei até mesmo desconfiado, será que tudo aquilo eu tinha inventado? Duas crianças disseram ter

11 Segundo Laplanche e Pontalis (1986), “o princípio de realidade é um princípio regulador do funcionamento psíquico que busca a obtenção no real das satisfações." 
medo de fantasma: "Tenho medo de fantasma, múmia." - "Quando eu vou dormir eu fico com medo que isso é real."

A experiência de participar da atividade "Hora do Conto", de conhecer e analisar as histórias e entrevistas, leva-nos a perceber uma identificação das crianças com algumas narrativas.

\section{Consideraçóes finais}

Partimos do pressuposto de que a escola é uma instituição social e, por isso, reflete contradições engendradas pela sociedade dominante. Assim, a escola, como parte dessa totalidade, traz para o seu cotidiano os valores sociais, políticos, ideológicos e culturais, os quais, por sua vez, participam da formação das crianças. Todavia, os profissionais da escola, quando conscientes do potencial desses valores aprendidos como elementos emblemáticos, devem se posicionar e pensar qual é o modelo de formação a que aspiram para seus alunos. Diante dessas considerações e a partir do contexto observado, buscamos, portanto, investigar a identificação das crianças com personagens e conteúdos das histórias contadas, elegendo para isso a "Hora do Conto". Teoricamente, consideramos que a Teoria Crítica da Sociedade, cuja orientação se destina a formar indivíduos humanos que contestem a violência, a barbárie e o consumismo, contribui para sanar a violência física e a miséria social.

Entendemos que há um consenso entre os profissionais da escola e a família de que o livro literário é um instrumento importante utilizado pelos professores para a prática da leitura e escrita dos alunos. Nessa perspectiva, a leitura literária não instrumentalizada, ou seja, trabalhada como arte, entendida como uma atividade criadora, na sua dimensão política, pode atingir e mobilizar o pensamento infantil. Sendo assim, possibilita à criança transpor a vivência do mundo sensível e aparente e refletir a realidade, criando experiências que podem se diferenciar do pensamento unilateral, unidimensional, e de atitudes padronizadas da "cultura do sempre idêntico" imposta pelos produtos da indústria cultural. É necessário que a leitura do livro literário fora do contexto escolar, como ocupação do tempo livre da criança, seja incentivada e orientada por pais e familiares. Não se ater a isso é deixar espaço aos produtos mais nocivos da indústria cultural, desde jogos eletrônicos violentos a propagandas de literatura duvidosa postadas na internet. A escolha do livro pelos adultos é ação política, ou seja, revela concepções ideológicas e posições frente à sociedade dominante. A cada livro lido, a possibilidade de a criança exercitar o pensamento criativo, na interface com o autor, consigo mesma e com a realidade, é lançada, criando-se outras experiências mediadas pela arte literária.

Isso posto, entendemos que o papel histórico da escola, especialmente nas primeiras séries do Ensino Fundamental, deve transpor a prática de transmitir o conhecimento construído pela humanidade e, pela aproximação com o texto literário impresso, ampliar o ensino com atividades culturais que privilegiem as relações humanas. Sabemos que a informática e a internet dispõem de jogos, brincadeiras, músicas e histórias literárias infantis, que são atrativos para as crianças, os quais integram atividades tanto escolares quanto familiares. Contudo, à escola 
cabe a tarefa de tornar o livro literário impresso um objeto também qualitativamente atrativo. Ressaltamos ainda que a escola é o espaço educativo por excelência para desenvolver a prática de leitura com a criança, já que, fora do ambiente escolar, ela pode vir a ocupar o seu tempo, de modo indevido ou exagerado, com a realidade virtual.

Assim, a julgar pelo nosso trabalho, a literatura infantil é um recurso fundamental que possibilita a construção de uma prática pedagógica criativa e reflexiva contribuindo com o processo formativo da criança lhe possibilitando pensar a realidade, instigar o pensamento crítico e a criação de novas experiências, capazes de sinalizar para a formação de uma humanidade com consciência crítica, autônoma e avessa a todo tipo de violência.

\section{Referências}

ADORNO, Theodor. Educação e emancipação. Trad. de Wolfgang Leo Maar. Rio de Janeiro: Paz e Terra, 1995.

HORKHEIMER, Max. Dialética do esclarecimento. Trad. de Guido A. Almeida. Rio de Janeiro: Zahar, 1991.

BEDRAN, Beatriz M. [Bia Bedran]. O videotinha. Site internet: www.letras.com.br/biabedran, 2008.

BENJAMIN, Walter. Sobre alguns temas em Baudelaire. Trad. de José M. Barbosa; Hemerson A. Baptista. In: Obras escolhidas III: Charles Baudelaire um lírico no auge do capitalismo. São Paulo: Brasiliense, 1989. Prefácio; Walter Benjamin ou a história aberta. In: Obras escolhidas; Magia e técnica, arte e política.

. A obra de arte na era de sua reprodutibilidade técnica. Trad. de Sérgio P.

Roaunet. In: Obras escolhidas: Magia e técnica, arte e política. São Paulo: Brasiliense, 1993.

CAPARELLI, Sérgio. Capitão sem fim. In: Poemas para crianças. Porto Alegre: Editora L\&PM, 2006.

COÊLHO, Ildeu M. Cultura, educação e escola. In: COÊLHO, Ildeu M. (Org.).

Educação, cultura e formação: o olhar da filosofia. Goiânia: Ed. PUC Goiás, 2009.

CROCHÍK, José Leon. Preconceito, indivíduo e cultura. 1. reimp. 3. ed. São Paulo: Casa do Psicólogo, 2011.

LANDIVAR, Clêidna. Entrevista de Gabriela Luccianni. Revista Nova Escola. Goiânia, $25 / 06$ a $01 / 06 / 2006$.

MEIRELES, Cecília. Problemas da literatura infantil. 3. ed. São Paulo, SP: Summus Editorial LTDA, 1979.

SIGUEMOTO, Regina. Anúncio no Jornal. São Paulo: Ed. do Brasil, 1996. 
VELOSO, Rui M. A obra de Aquilino Ribeiro para crianças: imaginário e escrita. Portugal, Porto: Porto Editora LTDA, 1994.

. Leitura literária, a filha bastarda da prática pedagógica. In: AZEVEDO,

Fernando et al. (Coord.). Imaginário, identidades e margens. Portugal, Vila Nova de Gaia: Edições Gailivro, 2007.

ZANOLLA, Sílvia R. S. Videogame; educação e cultura. Campinas, S.P: Editora Alínea, 2010a.

ZILBERMAN, Regina. A literatura Infantil na escola. 7. ed. Revista e Ampliada. São Paulo: Global, 1987.

- A leitura e o ensino da literatura: democracia, educação e leitura; a escolha do texto, segundo grau, vestibular e literatura. São Paulo; Contexto, 1988.

ZIRALDO \& ZÉLIO. A bela borboleta. São Paulo: Melhoramentos, 1980. 